\title{
Missed opportunities for prevention of perinatal transmission of hepatitis B: A retrospective cohort study
}

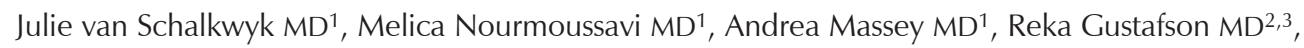 \\ Elizabeth Brodkin $\mathrm{MD}^{4}$, Martin Petric $\mathrm{PhD}^{5}$, Mel Krajden $\mathrm{MD}^{5}$, Simon Dobson $\mathrm{MD}^{6}$, Jane Buxton $\mathrm{MBBS}^{2}$, \\ Mark Bigham $\mathrm{MD}^{2}$, Neora Pick $\mathrm{MD}^{7}$, Richard Schreiber $\mathrm{MD}^{6}$, Christopher H Sherlock MBBS${ }^{5}$, \\ Deborah Money $\mathrm{MD}^{1}$, Eric M Yoshida $\mathrm{MD}^{7}$
}

\begin{abstract}
J van Schalkwyk, M Nourmoussavi, A Massey, et al. Missed opportunities for prevention of perinatal transmission of hepatitis B: A retrospective cohort study. Can J Gastroenterol Hepatol 2014;28(10):525-528.
\end{abstract}

BACKGROUND: Perinatal transmission of hepatitis B virus (HBV) can occur despite postexposure prophylaxis (PEP). Recent literature suggests that antiviral treatment during pregnancy when maternal HBV DNA levels are elevated can further decrease vertical transmission. However, HBV DNA screening is not routinely performed antenatally. OBJECTIVE: To determine the rates of HBV prevalence and perinatal transmission in an antenatal cohort.

METHODS: A retrospective review of public health records (December 2008 to December 2010) was performed for both mothers and newborns.

RESULTS: A total of 725 mother-infant pairs were included. Of these, 574 of $715(80 \%)$ women had antenatal hepatitis B e antigen (HBeAg) testing performed, and 127 of 574 (22\%) were HBeAg positive $(\mathrm{HBeAg}+)$. Of babies born to hepatitis $\mathrm{B}$ surface antigen-positive (HBsAg+) mothers, only 573 of $725(79 \%)$ received complete PEP. In addition, 172 of 725 (24\%) infants did not receive post-PEP blood testing or were lost to follow-up. Of the 552 infants with results available, seven cases $(1.3 \%)$ of mother-to-child HBV transmission were observed, six of which involved infants born to HBeAg+ women. CONCLUSIONS: Our findings suggest that routine HBeAg screening could identify a subset of mother-infant pairs among $\mathrm{HBsAg}+$ pregnant women who are at higher risk for vertical HBV transmission. Determination of viral load in expectant $\mathrm{HBeAg}+$ mothers may provide more precise insight into HBV transmission to their infants.

Key Words: Hepatitis B; Pregnancy; Vertical transmission

\section{Les occasions ratées de prévenir la transmission périnatale de l'hépatite $B$ : une étude de cohorte rétrospective}

HISTORIQUE : Le virus de l'hépatite B (VHB) peut être transmis pendant la période périnatale malgré une prophylaxie postexposition (PEP). D'après les publications récentes, un traitement antiviral pendant la grossesse, lorsque les taux d'ADN du VHB sont élevés, peut réduire davantage la transmission verticale. Cependant, l'ADN du VHB n'est pas dépisté systématiquement avant la naissance.

OBJECTIF : Déterminer la prévalence et la transmission périnatale du VIH dans une cohorte anténatale.

MÉTHODOLOGIE : Les chercheurs ont effectué une analyse rétrospective des dossiers de santé publique (décembre 2008 à décembre 2010) des mères et de leur nouveau-né.

RÉSULTATS : Au total, 725 dyades mère-nourrisson ont fait partie de l'étude. Ainsi, 574 femmes sur 715 (80\%) ont subi un test de dépistage anténatal de l'antigène e de l'hépatite $B$ (AgeHB), et 127 sur $574(22 \%)$ y étaient positives (AgeHB+). Chez les bébés nés d'une mère positive à l'antigène de surface de l'hépatite $\mathrm{B}(\mathrm{AgsHB}+)$, seulement 573 sur 725 (79\%) ont reçu une PEP complète. De plus, 172 des 725 nourrissons ( $24 \%$ ) n'avaient pas subi d'analyse sanguine après la PEP ou avaient été perdus au suivi. Des 552 nourrissons dont on connaissait les résultats, sept cas $(1,3 \%)$ de transmission du VHB de la mère au nourrisson ont été observés, dont six nés d'une mère AgeHB+. CONCLUSIONS : Selon nos observations, le dépistage systématique de l'AgeHB permettait de repérer un sous-groupe de dyades mèrenourrisson chez les femmes enceintes Ags $\mathrm{HB}+$ qui étaient plus vulnérables à la transmission verticale du VHB. En déterminant la charge virale des femmes AgeHB+ enceintes, on peut avoir un aperçu plus précis du risque de transmission du VHB à leur nourrisson.
$\mathrm{G}$ lobally, 350 million people are chronically infected with hepatitis J $B$ virus (HBV) (1). The risk of developing chronic infection correlates inversely with the age at which HBV infection is acquired because the majority of those infected perinatally develop chronic infection. Chronic HBV infection is associated with liver-related diseases such as hepatocellular carcinoma (2). Over the past three decades, perinatal transmission of HBV has been dramatically reduced by the use of postexposure prophylaxis (PEP) (3). In British Columbia, PEP consists of hepatitis B immunoglobulin ( $\mathrm{HBIg}$ ) and vaccine administration to the newborn at birth, followed by three additional doses at two, four and six months of age (4).

With PEP, the rate of vertical transmission is reported to be $1 \%$ to $2 \%$ for quiescent chronic carrier mothers (hepatitis B surface antigen positive $[\mathrm{HBsAg}+])$ but may be as high as $32 \%$ for mothers with active HBV infection (hepatitis B e antigen positive [HBeAg+]) (5).
The strongest predictor of vertical transmission is high levels of maternal serum HBV DNA. The presence of HBeAg generally correlates with high HBV DNA levels; however, $\mathrm{HBeAg}$ alone is not indicative of the magnitude of risk. For every log increase in HBV DNA level above $10^{6}$ copies $/ \mathrm{mL}$, the risk of PEP failure increases (6). Missed opportunities exist worldwide to prevent unnecessary HBV transmission such as use of full implementation of PEP as well as consideration of antiviral therapy in pregnancy to reduce the level of HBV DNA. Trials conducted in high HBV-endemic regions show that the use of antiviral medication in the last trimester of pregnancy, when maternal HBV DNA levels are $>10^{7}$ copies $/ \mathrm{mL}$, may reduce the rate of vertical transmission (7-10).

In the current study, we had three aims: to determine the prevalence of $\mathrm{HBsAg}$ and $\mathrm{HBeAg}$ among pregnant women in British Columbia; to determine the rate of perinatal HBV transmission in this

${ }^{1}$ Department of Obstetrics and Gynaecology; ${ }^{2}$ School of Population and Public Health, University of British Columbia; ${ }^{3}$ Office of the Medical Health

Officer, Vancouver Coastal Health Authority, Vancouver; ${ }^{4}$ Office of the Medical Health Officer, Fraser Health Authority, Surrey; ${ }^{5}$ Department of

Pathology and Laboratory Medicine; ${ }^{6}$ Department of Pediatrics; ${ }^{7}$ Department of Medicine, University of British Columbia, Vancouver, British Columbia Correspondence: Dr Julie van Schalkwyk, BC Women's Hospital and Health Centre, 4500 Oak Street, Vancouver, British Columbia V6H 3N1.

Telephone 604-875-2424, e-mail jvanschalkwyk@cw.bc.ca

Received for publication March 5, 2014. Accepted September 8, 2014 


\begin{tabular}{|c|c|c|c|c|}
\hline \multirow{2}{*}{$\begin{array}{l}\text { Infant HBsAg } \\
\text { status }\end{array}$} & \multicolumn{4}{|c|}{ Maternal HBeAg status* } \\
\hline & HBeAg- & $\mathrm{HBeAg}+$ & Unknown & Total \\
\hline HBsAg- & 337 & 100 & 108 & 545 \\
\hline $\mathrm{HBsAg}+$ & 0 & 6 & 1 & 7 \\
\hline Unknown & 110 & 21 & 42 & 173 \\
\hline Total & 447 & 127 & 151 & \\
\hline
\end{tabular}

Data presented as $n .{ }^{*} 10$ sets of twins within this sample. There were 725 motherinfant pairs, consisting of 715 women and 725 infants. Maternal data points for women with twins were counted twice. - Negative; + Positive
TABLE 2

Infant vaccine receipt history $(n=725)$

\begin{tabular}{|c|c|c|c|c|}
\hline \multirow[b]{2}{*}{ Vaccine(s) } & \multicolumn{4}{|c|}{ Completion of vaccine schedule } \\
\hline & Yes & No & Off-schedule* & Unknown \\
\hline $\mathrm{HBlg}$ & $681(93.9)$ & $31(4.3)$ & - & $13(1.8)$ \\
\hline $\begin{array}{l}\text { HBV vaccine } \\
\text { at birth }\end{array}$ & $698(96.3)$ & $1(0.1)$ & - & $26(3.6)$ \\
\hline $\begin{array}{c}\text { Complete } \\
\text { series }^{\dagger}\end{array}$ & $573(79.0)$ & $85(11.7)$ & $49(6.8)$ & $18(2.5)$ \\
\hline \multicolumn{5}{|c|}{$\begin{array}{l}\text { Data presented as } n(\%) .{ }^{*} \text { Defined as any dose that was administered at leas } \\
\geq 1 \text { month(s) off the recommended schedule; }{ }^{\dagger} \text { Defined as hepatitis } B \text { immuno- } \\
\text { globulin }(\mathrm{HBlg}) \text { and hepatitis } B \text { virus }(\mathrm{HBV}) \text { vaccine administered at birth, fol- } \\
\text { lowed by additional doses of } H B V \text { vaccine at two, four and six months of age } \\
\text { For at-risk infants born before February } 2009 \text {, four doses at zero, two, four ano } \\
\text { six months age were administered }\end{array}$} \\
\hline
\end{tabular}

The proportion of infants receiving HBV serological testing postprophylaxis (eight to 12 months of age), and the rate of immunoprophylaxis failure, as indicated by infants' HBsAg positivity despite PEP, were determined. Outcomes were stratified according to maternal HBeAg status.

\section{METHODS}

Study design

A retrospective review of the treatment and follow-up of infants born to $\mathrm{HBsAg}+$ women between December 2008 and December 2010 was undertaken. All pregnant women in two health authorities within British Columbia who tested and were reported to Public Health Services as $\mathrm{HBsAg}+$ were approached to participate. Inclusion criteria included a live birth during the study period to 12 months postenrollment (to account for deliveries that occurred $>40$ weeks after enrollment)

\section{Data collection}

Data regarding HBV infection status were compiled from two public health data registries: the Primary Access Regional Information System, used by the Vancouver Coastal Health Authority, and the integrated Public Health Information System, used by the Fraser Health Authority. Data were cross-matched between public health records and the British Columbia Public Health Microbiology and Reference Laboratory at the British Columbia Centre for Disease Control, which perform reflex $\mathrm{HBeAg}$ testing on $\mathrm{HBs} A g+$ prenatal specimens. The data extraction identified a cohort of women with confirmed HBV infection who were pregnant or became pregnant during the study period.

$\mathrm{HBs} \mathrm{Ag}+$ pregnant women identified through the data registries were contacted antenatally by public health nurses and informed of their diagnosis, provided with recommendations for treatment of their infants and follow-up testing. The women's care providers were also contacted by mail and informed of the risk of perinatal HBV transmission and the standard PEP protocol. Follow-up contact to mothers was made at eight to 12 months postpartum to collect information on maternal age, singleton versus multiple gestation status, gestational age at delivery, mode of delivery, breastfeeding, details of PEP receipt and results of follow-up infant testing.

\section{Data analysis}

Deidentified data were verified, entered and stored in a database. Descriptive statistics were applied to calculate the rate of maternal infection and the rate of perinatal HBV transmission, the proportion of infants who received complete HBV PEP (HBIg within $24 \mathrm{~h}$ of birth and three doses of HBV vaccine at zero, one and six months of age or, for at-risk infants born before February 2009, four doses at zero, two, four and six months of age). This change in HBV vaccination schedule in British Columbia for infants of HBV-infected mothers was incorporated into the current study. Off-schedule vaccine receipt was defined as any dose that was administered at least $\geq 1$ month off the recommended schedule.

\section{RESULTS}

\section{Maternal HBV carrier rate}

In total, 725 mother-infant pairs (10 sets of twins) were identified in whom maternal HBsAg screening was positive between December 2008 and December 2010. The total number of deliveries within the corresponding health regions in British Columbia during the same time frame was 55,754 (British Columbia Vital Statistics Agency, 2008, 2009), corresponding to an overall maternal HBV carrier rate of $1.3 \%$. Of the 725 mother-infant pairs identified, 574 (79\%) underwent maternal antenatal $\mathrm{HBeAg}$ testing. Of these, 127 (22.1\%) women were $\mathrm{HBeAg}+$. Follow-up infant testing results, performed to determine whether perinatal transmission had occurred, were not performed or not available in the public health databases for 173 (23.8\%) infants.

Perinatal HBV transmission rate

Of the 552 infants who had available follow-up HBV testing results, perinatal transmission was observed in seven $(1.3 \%)$ cases. In the groups of women who were $\mathrm{HBeAg}+$ and $\mathrm{HBeAg}$ negative, vertical transmission rates were $5.5 \%(n=6)$ and $0 \%(n=0)$, respectively (Table 1$)$. One transmission occurred in a mother who did not undergo HBeAg testing.

Infant vaccine history

Most infants received the first of dose HBV vaccination (96.3\%) and HBIg (93.9\%) shortly after birth (Tables 2 and 3). However, approximately $20 \%$ did not receive the postbirth vaccination doses as per the provincial public health recommended schedule. Some infants $(11.7 \%)$ did not complete their vaccination series, while another portion of infants $(6.8 \%)$ received their immunoprophylaxis off schedule.

Clinical characteristics of $\mathrm{HBV}$-positive infants

The clinical characteristics of the seven HBV-positive infants are described in Table 4. When the association of infant HBsAg positivity and PEP completion rates were examined, all seven infants who acquired HBV infection received vaccine, albeit two off-schedule. Of the seven infants who tested positive for $\mathrm{HBs} \mathrm{Ag}$, one was documented to have anti-HBs levels that would have been considered immune in the absence of HBsAg. Of the seven HBsAg+ infants, breastfeeding data were available for five, all of whom were breastfed. Five were delivered vaginally and two by Caesarean section. Of the $545 \mathrm{HBsAg}$ negative infants, breastfeeding data were available for 304: $271(89.1 \%)$ were breastfed, 31 (10\%) were not breastfed and two $(0.66 \%)$ received donor milk. 
TABLE 3

Infant hepatitis B surface antigen (HBsAg) status and vaccine receipt

\begin{tabular}{|c|c|c|c|c|c|c|c|}
\hline \multirow[b]{3}{*}{ Infant HBsAg status } & \multicolumn{7}{|c|}{ Vaccine completion } \\
\hline & \multicolumn{2}{|c|}{ HBIg } & \multicolumn{2}{|c|}{ HBV vaccine at birth } & \multicolumn{3}{|c|}{ Complete vaccine series } \\
\hline & Yes & No & Yes & No & Yes & Off-schedule* & No \\
\hline Negative & 513 & 25 & 527 & 1 & 469 & 37 & 30 \\
\hline Total $^{\dagger}$ & 520 & 25 & 543 & 1 & 474 & 39 & 30 \\
\hline
\end{tabular}

Data presented as $n$. *Defined as any dose that was administered at least $\geq 1$ month(s) off the recommended schedule; ${ }^{\dagger}$ Totals are variable because not all infants had data available for all points of hepatitis $B$ virus (HBV) immunoglobulin (HBlg)/vaccine receipt in addition to infant hepatitis $B$ surface antigen (HBsAg) testing

TABLE 4

Virology and delivery characteristics of hepatitis B surface antigen (HBsAg)-positive infants $(n=7)$

\begin{tabular}{|c|c|c|c|c|c|c|c|c|}
\hline Case number & Year of birth & $\begin{array}{c}\text { Maternal } \\
\text { HBeAg status }\end{array}$ & $\begin{array}{c}\text { HBsAg status } \\
\text { post-PEP }\end{array}$ & Anti-HBs & $\begin{array}{l}\text { Adequate } \\
\text { immunity }\end{array}$ & PEP receipt & Mode of delivery & Breastfeeding* \\
\hline 1 & 2008 & Positive & Positive & Negative & Not immune & Off-schedule $^{\dagger}$ & Vaginal (forceps) & Partial \\
\hline 2 & 2008 & Positive & Positive & Negative & Not immune & Complete & Vaginal (vacuum) & Exclusive \\
\hline 3 & 2008 & Positive & Positive & Negative & Not immune & Complete & Vaginal (SVD) & Exclusive \\
\hline 4 & 2009 & Positive & Positive & Positive & Immune & Off-schedule & Caesarean section & Unknown \\
\hline 5 & 2009 & Positive & Positive & Negative & Not immune & Complete & Vaginal (SVD) & Unknown \\
\hline 6 & 2009 & Unknown & Positive & Negative & Not immune & Complete & Vaginal (SVD) & Exclusive \\
\hline 7 & 2010 & Positive & Positive & Negative & Not immune & Complete & Caesarean section (elective) & Partial \\
\hline
\end{tabular}

${ }^{*}$ Partial, supplemented breast milk with formula; exclusive, breast milk only; ${ }^{\dagger}$ Defined as any dose that was administered at least $\geq 1$ month(s) off the recommended schedule. HBeAg Hepatitis B e antigen; HBs Hepatitis B surface antigen; PEP Postexposure prophylaxis; SVD Spontaneous vaginal delivery

\section{DISCUSSION}

Main findings

Approximately $1.3 \%$ of the pregnant cohort studied was $\mathrm{HBs} \mathrm{Ag}^{+}$, of whom one in five were also $\mathrm{HBeAg}+$. Of the babies born to the HBVpositive mothers, $20 \%$ did not receive PEP as per the recommended provincial public health schedule. In addition, almost one-quarter of infants did not undergo the recommended post-PEP serological testing at eight to 12 months of age to confirm PEP effectiveness.

Of the 552 infants who underwent post-PEP testing, seven cases of mother-to-child transmission (MTCT) were documented, corresponding to a $1.3 \%$ vertical transmission rate. This rate is lower than the perinatal HBV transmission rate of $2.1 \%$ that was reported in an adjacent Canadian province (Alberta) among a cohort of 980 exposed infants (11). Significantly, the maternal $\mathrm{HBeAg}$ was positive in six of the seven cases of perinatal transmission in the study, all of whom had completed PEP, suggesting that high maternal serum levels of HBV DNA was a likely significant factor in PEP failure. Because HBV viral loads were not captured in the databases and may not have been routinely ordered during the study period, these values were not available for analysis. The seventh case of transmission occurred from a mother with unknown $\mathrm{HBeAg}$ status.

Strengths and limitations

The present study represents an important evaluation of the efficacy of standardized HBV perinatal PEP in a jurisdiction with standardized guidelines and full medical coverage under these circumstances. It represents the two largest health authorities in British Columbia, which include a representative sample of provincial births because $63 \%$ occur within these regions (12). In addition, the ethnic composition within these regions is highly diverse, with $27 \%$ of the population identifying as Asian and 10\% identifying as South Asian (13).

These data have several limitations. First, the present study was retrospective in design; however, the study reveals the current practice of maternal HBV testing, PEP receipt and follow-up testing in British Columbia, in the absence of observational bias. The data sets were incomplete and there were insufficient data available to fully assess the maternal and neonatal factors that may influence transmission. For example, we are unaware of whether any women were treated with antenatal antivirals in these pregnancies because this information was not collected. In addition, other potential risk factors, such as the duration of breastfeeding and whether it was supplemented with formula, the duration of labour, rupture of membranes or invasive fetal testing information was unavailable. Recent evidence suggests, however, that breastfeeding is not associated with a significant, incrementally increased risk for HBV vertical transmission among immunized infants (14).

\section{Interpretation}

Despite the introduction of PEP programs with proven efficacy for decreasing HBV transmission (15), almost 20\% of infants in the present study did not complete their vaccination series, even though their parents and health care providers received specific PEP instructions as part of the public health program. Issues that may contribute to incomplete vaccine receipt include language barriers and family relocation, resulting in challenges for public health staff to assess vaccine uptake and subsequent infant testing results. Health care provider recommendation is associated with vaccine uptake (16). Because vaccination is the single most effective way of preventing HBV infection, programs designed to target patients with vaccine adherence challenges are paramount.

Canadian hepatology guidelines published in 2012 on the management of chronic hepatitis B recommend that all pregnant women who are $\mathrm{HBs} \mathrm{Ag}+$ have HBV DNA levels determined (17). Higher rates of PEP failure occur with increasing HBV DNA levels (6). These guidelines also recommend that antiviral therapy be considered for pregnant women with HBV DNA viral loads $>2 \times 10^{6} \mathrm{IU} / \mathrm{mL}$, in an effort to prevent PEP failure and vertical transmission.

In the present study, six of seven transmissions that occurred were in women who tested positive for $\mathrm{HBeAg}$. Had these women been treated with antenatal antiviral therapy, as suggested in several treatment trials $(7-10)$, these neonatal infections may have been prevented.

Mutations in the HBsAg region can occur in vertical maternal transmission of HBV under the immunological selection pressure of PEP $(18,19)$. One such transmission was observed in an Alberta cohort, in which maternal $\mathrm{HBeAg}$ and HBV DNA levels were undetectable in the first trimester (20). Of interest, and of potential concern, is the infant who was infected with HBV (as indicated by HBsAg seropositivity) despite a serum anti-HBs titre that was in the protective range (Table 4). Although molecular sequencing was not 
performed in this particular case, it is possible that a similar phenomenon may have contributed to a possible explanation for PEP prophylaxis failure in this instance. This phenomenon, although uncommonly documented, provides additional rationale for identifying HBV-infected mothers at higher risk for vertical HBV transmission and administering selective antiviral treatment in those cases, in addition to the currently recommended PEP and post-PEP serological assessment.

\section{CONCLUSION}

A significant proportion of infants in British Columbia born to $\mathrm{HBsAg}+$ mothers are not receiving a full course of recommended PEP and/or have incomplete follow-up. Moreover, MTCT of HBV still occurs despite complete, timely HBV PEP, which particularly affects infants whose mothers are $\mathrm{HBeAg}+$. The present study does not add any new data to what is known about HBV transmission; however, our findings highlight that adherence to PEP clinical guidelines in British Columbia is suboptimal and needs improvement, and may be relevant to other Canadian jurisdictions facing similar challenges.

While a growing body of evidence indicates that maternal antiviral treatment can abrogate HBV vertical transmission in maternal $\mathrm{HBeAg}+$ cases, investigations on maternal and fetal antiviral toxicities, rebound hepatitis after treatment cessation, safety of breastfeeding during treatment and the treatment-associated emergence of viral drug resistance are still needed. The optimal timing for $\mathrm{HBe} A g$ or HBV DNA testing in pregnancy in relation to risk determination for MTCT remains uncertain. Future studies may aim to identify modifiable perinatal risk factors in $\mathrm{HBs} \mathrm{Ag}+$ women to further reduce the risk of HBV vertical transmission and the global burden of HBV disease.

ACKNOWLEDGEMENTS: This research was supported by a research grant from the British Columbia Children's Hospital Foundation, research funding from the British Columbia Hepatitis Program and the Women's Health Research Institute. The authors also thank the Women's Health Research Institute for providing careful editing of the manuscript.

\section{REFERENCES}

1. World Health Organization. Fact sheet N²04 July 2012. $<$ www.who.int/mediacentre/factsheets/fs204/en/> (Accessed June 16, 2013).

2. Kuo A, Gish R. Chronic hepatitis B infection. Clin Liver Dis 2012;16:347-69.

3. Centers for Disease Control and Prevention (CDC). Assessing completeness of perinatal hepatitis B virus infection reporting through comparison of immunization program and surveillance data - United States. MMWR 2011;60:410-3.

4. BC Centre for Disease Control. BC Routine Immunization Schedule for Infants \& Children Ages 0-6. < www.bccdc.ca/ imm-vac/ImmunizationSchedules/default.htm $>$ (Accessed September 24, 2014)
5. Chen HL, Lin LH, Hu FC, et al. Effects of maternal screening and immunization to prevent mother-to-infant transmission of HBV. Gastroenterology 2012;142:773-81,e2.

6. Pan C, Han GR, Zhao W, Xu C, Ge C. Virologic factors associated with failure to passive-active immunoprophylaxis in infants with HBsAg-positive at birth. Hepatology 2011;54(Suppl 4):878A.

7. Xu WM, Cui YT, Wang L, et al. Lamivudine in late pregnancy to prevent perinatal transmission of hepatitis $\mathrm{B}$ virus infection: A multicentre, randomized, double-blind, placebo-controlled study. J Viral Hepat 2009;16:94-103.

8. Van Zonneveld M, Van Nunen AB, Niesters HG, et al. Lamivudine treatment during pregnancy to prevent perinatal transmission of hepatitis B virus infection. J Viral Hepat 2003;10:294-7.

9. Pan CQ, Mi LJ, Bunchorntavakul C, et al. Tenofovir disoproxil fumarate for prevention of vertical transmission of hepatitis $B$ virus infection by highly viremic pregnant women: A case series. Dig Dis Sci 2012;57:2423-9.

10. Han GR, Cao MK, Zhao W, et al. A prospective and open-label study for the efficacy and safety of telbivudine in pregnancy for the prevention of perinatal transmission of hepatitis $\mathrm{B}$ virus infection. J Hepatol 2011;55:1215-21.

11. Plitt SS, Somily AM, Singh AE. Outcomes from a Canadian Public Health prenatal screening program for Hepatitis B 1997-2004. Can J Public Health 2007;98:194-7.

12. BC Vital Statistics Agency. Selected Vital Statistics and Health Status Indicators. Victoria: Ministry of Health; 2008, 2009. <www.vs.gov.bc.ca/stats/annual/> (Accessed September 24, 2014)

13. Statistics Canada. Ethnicity by province or territory. <www.statcan.gc.ca/> (Accessed September 24, 2014).

14. Zhang L, Gui X, Fan J, et al. Breast feeding and immunoprophylaxis efficacy of mother-to-child transmission of hepatitis B virus. Matern Fetal Neonatal Med (Epub ahead of print).

15. Stevens CE, Toy PT, Tong MJ, et al. Perinatal hepatitis B virus transmission in the United States. Prevention by passive-active immunization. JAMA 1985;253:1740-5.

16. Bigham M, Remple VP, Pielak K, McIntyre C, White R, Wu W. Uptake and behavioral and attitudinal determinants of immunization in an expanded routine hepatitis B vaccination program in British Columbia. Can J Public Health 2006;97:90-5.

17. Coffin C, Fung S, Ma M. Management of chronic hepatitis: Canadian Association for the Study of the Liver consensus guidelines. Can J Gastroenterol 2012;26:917-38.

18. Hino K, Okuda M, Hashimoto, et al. Glycine-to-arginine substitution at codon 145 of the $\mathrm{HBsAg}$ in two infants born to hepatitis B e antigen positive carrier. Dig Dis Sci 1995;40:566-70.

19. Hsu HY, Chang MH, Ni YH, Lin HH, Wang SM, Chen DS. Surface gene mutants of hepatitis B virus in infants who develop acute or chronic infection despite immunoprophylaxis. Hepatology 1997;26:786-91.

20. Singh AE, Plitt SS, Osiowy C, et al. Factors associated with vaccine failure and vertical transmission of hepatitis B among a cohort of Canadian mothers and infants. J Viral Hepat 2011;18:468-73. 


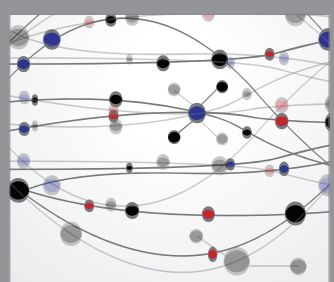

The Scientific World Journal
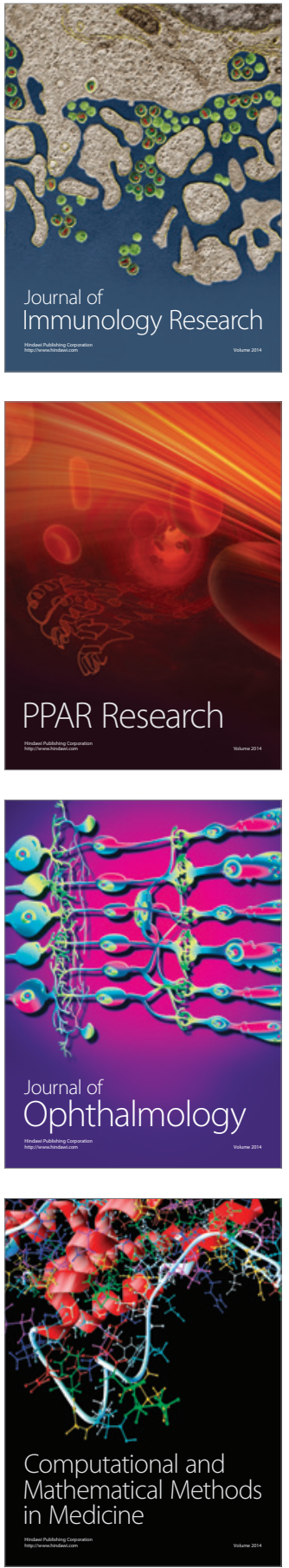

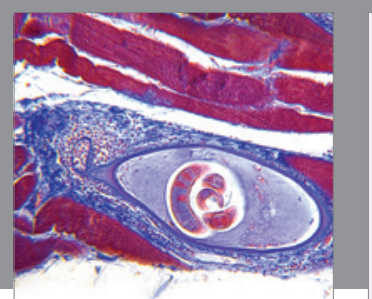

Gastroenterology Research and Practice

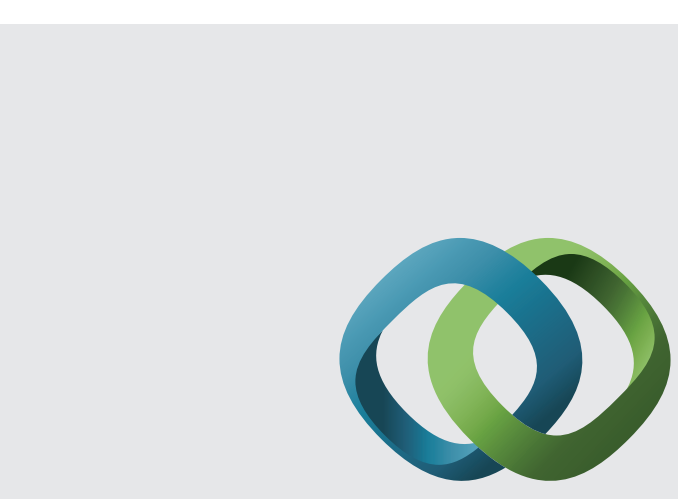

\section{Hindawi}

Submit your manuscripts at

http://www.hindawi.com
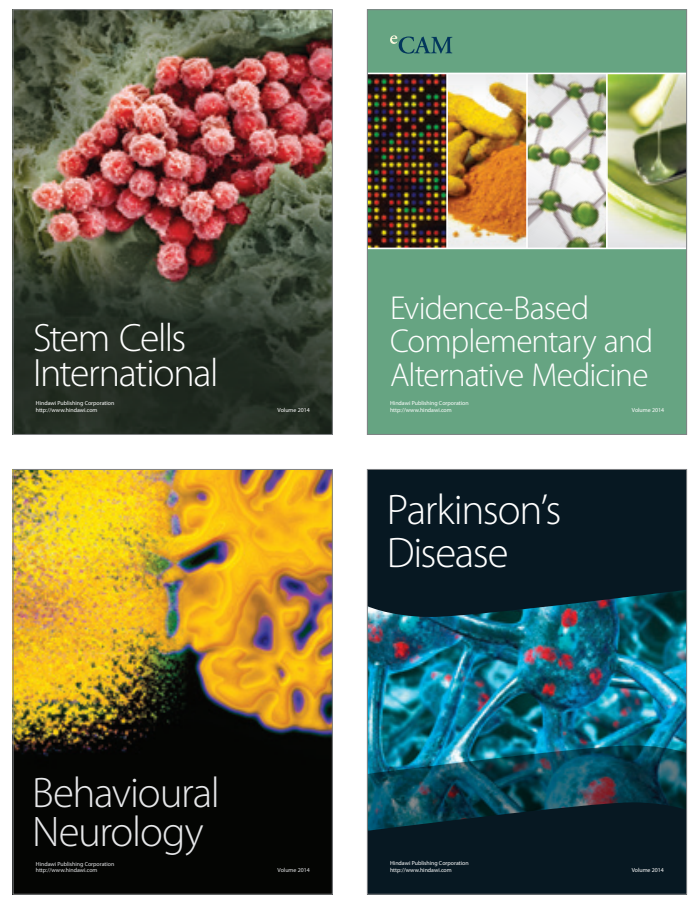
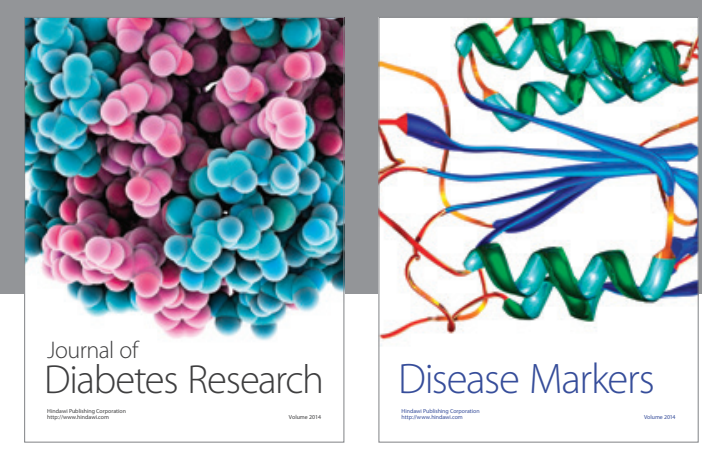

Disease Markers
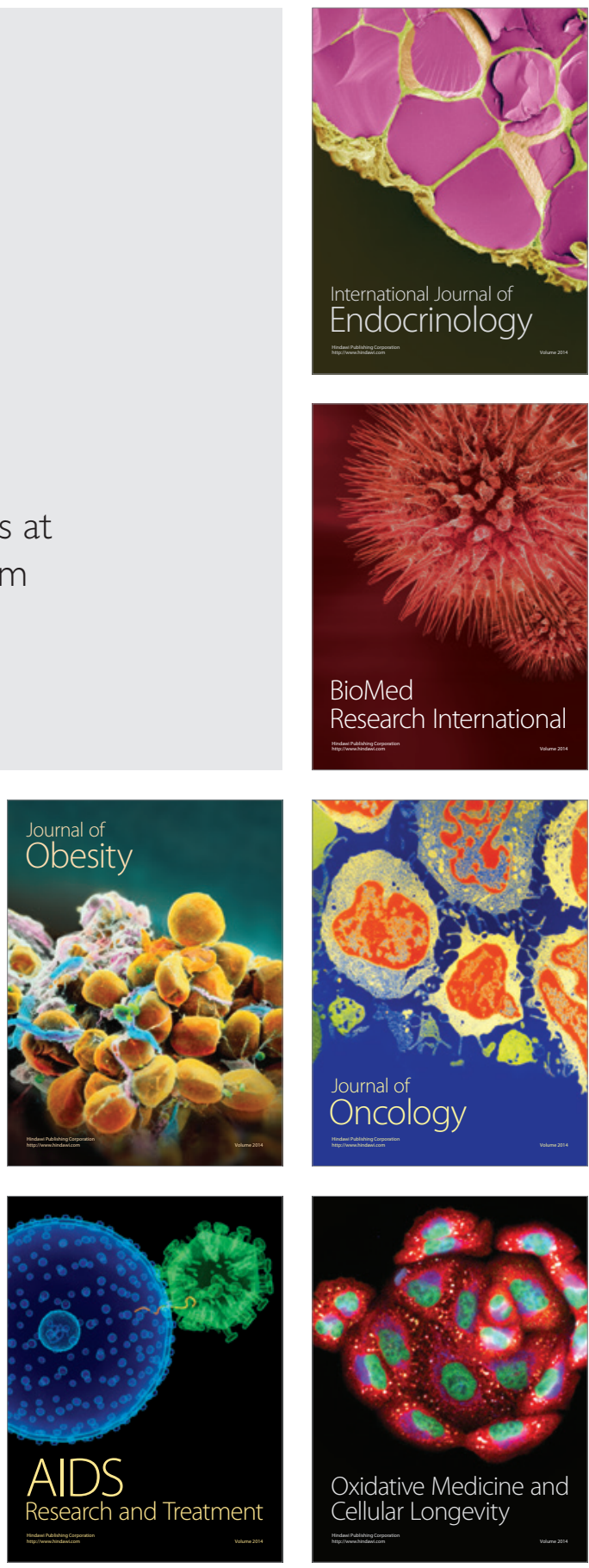